\title{
Photochemical Dehydrogenation, Ring Contraction, and Ring Expansion of Hydrogenated Derivatives of Benzoxazino-benzoxazine, Quinoxalino- quinoxaline, and Bibenzothiazole
}

\author{
Erich Tauer * and Karl-Heinz Grellmann \\ Max-Planck-Institut für Biophysikalische Chemie, Abteilung Spektroskopie, \\ Postfach 2841, D-3400 Göttingen
}

Received November 13, 1989

Key Words: Photochemistry / Benzoxazino-benzoxazines / Quinoxalino-quinoxalines / Bibenzothiazoles

The photochemical properties of the title compounds have been investigated and compared. The benzoxazino-benzoxazine derivatives 1 are photochemically converted into hydrogenated oxazole derivatives. In some cases this ring contraction is accompanied by a dehydrogenation reaction whereby the heterocyclic ring system becomes aromatic. Hydrogenated quinoxalino-quinoxalines also undergo a photodehydrogena- tion reaction and become aromatic. However, a ring contraction yielding the imidazolyl system does not take place. The only investigated sulfur-containing analog has different properties. The stable form is the bibenzothiazole 23 which contains a five-membered heterocyclic ring system. Photochemically 23 rearranges under ring expansion to give the benzothiazino-benzothiazine 24 .
As we have shown recently, the condensation of 2-aminophenol with glyoxal (molar ratio 2:1) yields 5a,6,11a,12tetrahydro[1,4]benzoxazino[3,2-b][1,4]benzoxazine (1), whose structure has been verified by X-ray analysis ${ }^{1}$. This compound has interesting photochemical properties which depend on the wavelength of the exciting light. Irradiation of an air-equilibrated solution of 1 in an alkane solvent $(\mathrm{CH})$, with light of wavelength $\lambda \geq 260 \mathrm{~nm}$ yields the dihydrobibenzoxazole 3 with $12 \%$ chemical yield. Short-wavelength excitation $(\lambda<260 \mathrm{~nm})$ also leads to the formation of 3 but, in addition, [1,4]benzoxazino[3,2-b][1,4]benzoxazine (5) is produced in $4 \%$ chemical yield (Scheme 1). Evidently, only short-wavelength excitation affords a photoproduct in which the four six-membered ring system of the parent compound 1 is still intact, but rearrangement to bibenzoxazolelike structures occurs apparently with much higher efficiency.

In Scheme 1 we assume that the primary photooxidation product has the structure 2 in the reaction path $1 \rightarrow 3$, and structure 4 in the "short-wavelength" path $\mathbf{1} \rightarrow \mathbf{5}$. The first stable photoproduct, 3 , of the "long-wavelength" pathway is formed after the absorption of one photon under elimination of two hydrogen atoms. (The absorption of a second photon is required to convert 3 into the oxidation product bibenzoxazole.) In the other route, absorption of just one photon yields as the first stable photoproduct the benzoxazino-benzoxazine 5 where four hydrogen atoms have been eliminated. The second step in this reaction $(\mathbf{4} \rightarrow \mathbf{5})$ is presumably a thermal reaction. Neither 2 nor 4 could be detected directly.

In this paper we discuss some experimental results obtained with compounds related to 1 . In the first group of these compounds the hydrogen atoms at the central carbon atoms $\left(\mathbf{R}^{1}, \mathbf{R}^{2}\right)$ or at the nitrogen atoms $\left(\mathbf{R}^{3}, \mathbf{R}^{4}\right)$ are replaced by substituents. In the second group, the oxygen atoms of
Scheme 1

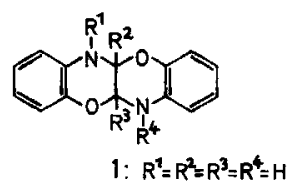
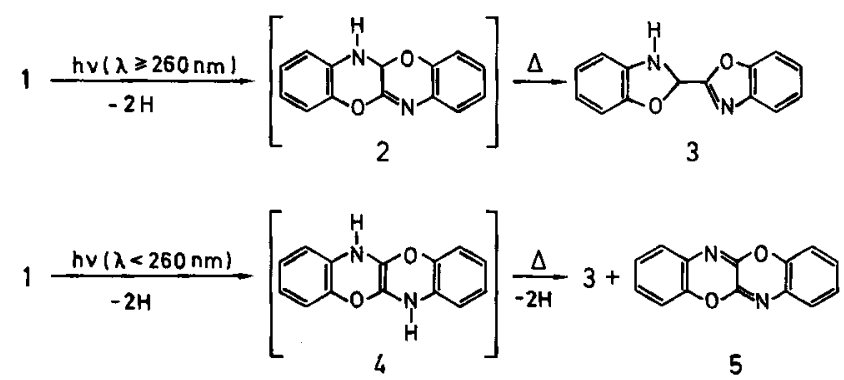

\begin{tabular}{l|llll} 
& $\mathrm{R}^{1}$ & $\mathrm{R}^{2}$ & $\mathrm{R}^{3}$ & $\mathrm{R}^{4}$ \\
\hline 1 & $\mathrm{H}$ & $\mathrm{H}$ & $\mathrm{H}$ & $\mathrm{H}$ \\
$1 \mathrm{a}$ & $\mathrm{H}$ & $\mathrm{H}$ & $\mathrm{CH}_{3}$ & $\mathrm{CH}_{3}$ \\
$1 \mathrm{~b}$ & $\mathrm{CH}_{3}$ & $\mathrm{H}$ & $\mathrm{H}$ & $\mathrm{H}$ \\
$1 \mathrm{c}$ & $\mathrm{C}_{6} \mathrm{H}_{5}$ & $\mathrm{H}$ & $\mathrm{H}$ & $\mathrm{H}$ \\
$1 \mathrm{~d}$ & $\mathrm{CH}_{3}$ & $\mathrm{CH}_{3}$ & $\mathrm{H}$ & $\mathrm{H}$ \\
$1 \mathrm{e}$ & $\mathrm{C}_{6} \mathrm{H}_{5}$ & $\mathrm{C}_{6} \mathrm{H}_{5}$ & $\mathrm{H}$ & $\mathrm{H}$ \\
$1 \mathrm{f}$ & $\mathrm{CH}_{3}$ & $\mathrm{C}_{6} \mathrm{H}_{5}$ & $\mathrm{H}$ & $\mathrm{H}$
\end{tabular}

1 are replaced by $\mathrm{NH}, \mathrm{NCH}_{3}$ or $\mathrm{S}$. The purpose of these modifications was originally to reduce the number of photooxidizable hydrogen atoms of 1 at selected sites in the hope to obtain photoproducts with structures related to the hypothetical intermediates 2 and 4, in order to put their postulation on firmer grounds. These efforts were awarded only with modest success. It turned out that the investigated 
derivatives and analogs of 1 have in part rather unexpected photochemical properties a number of which are described in this paper.

\section{Modification of the NH Groups of 1}

If in the parent compound $\mathbf{1}$ the hydrogen atoms $\mathbf{R}^{3}$ and $\mathrm{R}^{4}$ are replaced by $\mathrm{R}^{3}=\mathrm{R}^{4}=\mathrm{CH}_{3}$, no photooxidation at the central $\mathrm{C}-\mathrm{C}$ bridge takes place with appreciable yield, i.e. the $\mathrm{N}$-methylated analogon to 4 (Scheme 1) could not be detected. Instead, 1 a (Scheme 2) rearranges to 2,2',3,3'tetrahydro-3,3'-dimethyl-2,2'-bibenzoxazole (6). The chemical yield is $70 \%$ in degassed cyclohexane $(\mathrm{CH})$. In air-equilibrated $\mathrm{CH}$ the yield is much lower $(3-5 \%)$ and side reactions take place, which have not been investigated in detail. The yield of the reaction $1 \mathrm{a} \rightarrow \mathbf{6}$ is independent of the wavelength of the exciting light both in degassed and airequilibrated solution. In the crystalline state and in neutral solution, $\mathbf{6}$ is a stable compound. Traces of acids in solvents like ethanol or chloroform reconvert 6 quickly into 1 a. (This can cause problems if NMR spectra of $\mathbf{6}$ are taken in $\mathrm{CDCl}_{3}$ as solvent which may contain hydrochloric acid.)

Scheme 2

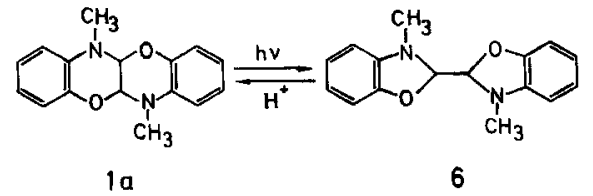

\section{Modification at the Central C-C Bridge of 1}

On irradiation of a degassed solution of $1 \mathrm{~b}\left(\approx 10^{-4} \mathrm{M}\right)$ in $\mathrm{CH}$ a compound with two absorption maxima at $\lambda=375$ and $390 \mathrm{~nm}$ is formed. On standing in the dark, this spectrum does neither change in the presence nor in the absence of oxygen. If the solution is concentrated by evaporation of the solvent under reduced pressure or with a stream of nitrogen, the absorption spectrum changes irreversibly and the absorption maximum at $\lambda=390 \mathrm{~nm}$ disappears. The finally isolated photoproduct 2-[1-(2-benzoxazolyl)ethylideneamino]phenol (9) shows an absorption maximum at $375 \mathrm{~nm}$. It was identified by comparison with an authentic sample (mixed melting point). Presumably, the primary photooxidation product of $\mathbf{1 b}$ is the benzoxazine derivative $\mathbf{7}$, as indicated in Scheme 3. However, benzoxazines of this type absorb at wavelengths shorter than $390 \mathrm{~nm}$. We therefore assume that 7 rearranges quickly to 8 which has an extented conjugated $\pi$-electron system.

A solution of $\mathbf{8}$ in $\mathrm{CH}$ is hydrolyzed by addition of a small amount of water. In agreement with the proposed structure of 8 , the hydrolysis products are 3-methyl- $2 H$-1,4-benzoxazin-2-on (10) and 2-aminophenol (11). The hydrolysis of 9 , on the other hand, yields 1-(2-benzoxazolyl)ethanon (12) and 11 (cf. Scheme 3).

In $1 \mathrm{c}$ the $5 \mathrm{a}$-methyl group of $\mathbf{1 b}$ is replaced by a phenyl group. The result of this substitution is a drastic change of the chemical and photochemical properties. A freshly prepared solution of $1 \mathrm{c}$ in $\mathrm{CH}$ has an absorption spectrum with
Scheme 3

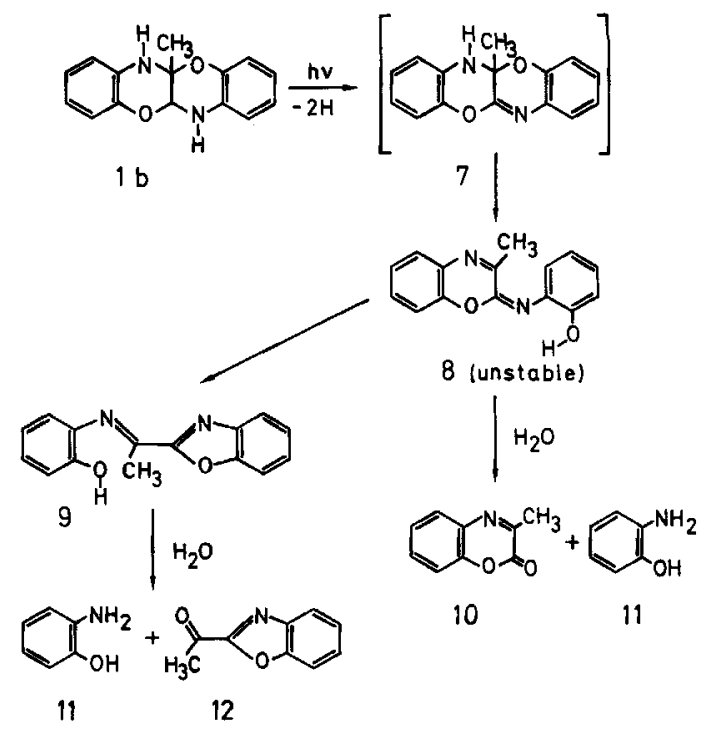

a maximum at $\lambda=289 \mathrm{~nm}$ and an extinction coefficient at this wavelength of $\varepsilon(289)=8370 \mathrm{M}^{-1} \mathrm{~cm}^{-1}$. On standing at room temperature, a second absorption maximum at 315 $\mathrm{nm}$ develops with a "half life" of about $45 \mathrm{~min}$. This process is reversible: If the solvent is removed by evaporation, $\mathbf{1 c}$ recrystallizes and exhibits the spectrum of the freshly prepared solution if the recovered crystals are dissolved again. In analogy to the findings of Belgodere et al. ${ }^{2)}$ who investigated the condensation products of 2-aminophenol and $\alpha$-dicarbonyl compounds, we assume that this change of the absorption spectrum is due to the formation of one isomer or an equilibrium of several isomers, the possible structures of which are shown in Scheme 4.

Scheme 4

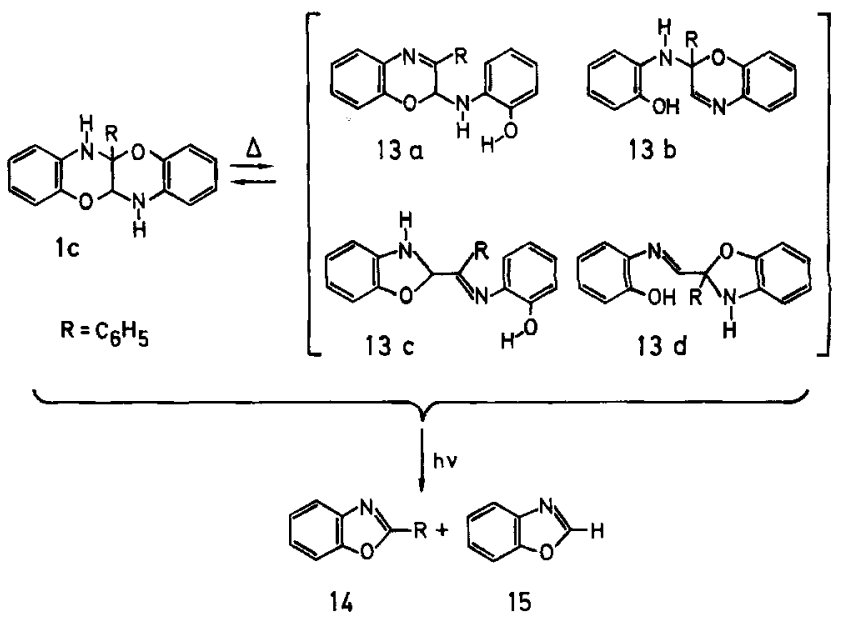

Irradiation of a degassed or of an air-equilibrated solution of $1 \mathrm{c}$ in $\mathrm{CH}$ yields as main products 2-phenylbenzoxazole (14) and benzoxazole (15). The irradiation time was considerably longer $(\approx 8-24 \mathrm{~h})$ than the time needed to establish the equilibrium $1 \mathrm{c} \rightleftharpoons \mathbf{1 3}$ (Scheme 4). In degassed solution a small amount of a compound is formed which has two 
absorption maxima at 390 and $410 \mathrm{~nm}$. It is presumably the analog of 8 (cf. Scheme 3). The benzoxazoles 14 and 15 are not formed in equal chemical yields (cf. Table 1), the yields depending on the excitation wavelength.

Table 1. Chemical yield of 2-phenylbenzoxazole (14) and benzoxazole (15) obtained by irradiation of $10^{-4} \mathrm{M}$ solutions of $1 \mathrm{c}$ in $\mathrm{CH}$. The yields were determined from the absorption spectra of the irradiated solutions.

\begin{tabular}{ccccc}
\hline $\begin{array}{c}\text { Excitation } \\
\text { wavelength } \\
{[\mathrm{nm}]}\end{array}$ & $\begin{array}{c}\text { Air-equilibrated } \\
\text { 2-Phenylbenz- } \\
\text { oxazole }\end{array}$ & Benzoxazole & $\begin{array}{c}\text { 2-Phenylbenz- } \\
\text { oxazole }\end{array}$ & Benzoxazole \\
\hline 254 & 18 & 9 & 18 & 11 \\
$\geq 280$ & 31 & 11 & 30 & 10 \\
\hline
\end{tabular}

Replacement of both central 5a,11a-hydrogen atoms of 1 by methyl (1d), phenyl (1e) or methyl- and phenyl groups (1f) yields derivatives which, in contrast to the 5a-phenyl derivative $1 \mathrm{c}$ do not isomerize in solution. However, similar to $\mathbf{1 c}$ (cf. Scheme 4) irradiations of solutions of 1d, $1 \mathrm{e}$ and $1 \mathrm{f}$ in $\mathrm{CH}$ (degassed or air-equilibrated) led to the formation of 2-substituted benzoxazoles, as shown in Scheme 5. The photoproducts were chromatographically separated and identified by comparison with the UV spectra and the GC and TLC retention times of authentic samples.

Scheme 5

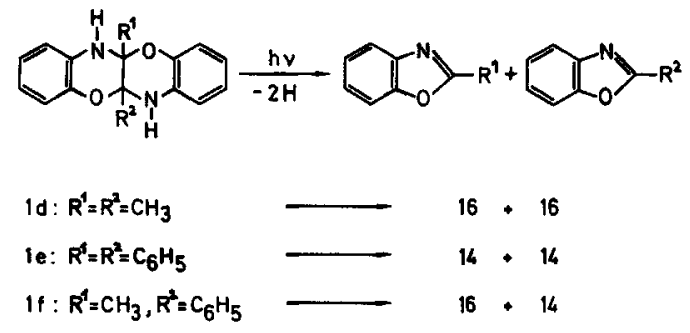

The chemical yields of the formation of 14 and 2-methylbenzoxazole (16) were estimated (cf. Table 2 ) by irradiation of $1 \times 10^{-4} \mathrm{M}$ solutions of $1 \mathrm{~d}, 1 \mathrm{e}$ or $1 \mathrm{f}$ until the characteristic benzoxazole UV-absorption peaks ceased to develop further. The values obtained by this method are not very accurate, but they show that the formation of 2-R-benzox-

Table 2. Chemical yield (\%) of 2-methylbenzoxazole and/or 2-phenylbenzoxazole obtained by photoreaction of compounds $1 \mathrm{~d}$, $1 e$ and $1 f$

\begin{tabular}{|c|c|c|c|c|c|c|c|}
\hline \multirow[b]{3}{*}{ Product } & \multirow[b]{3}{*}{$\begin{array}{l}\text { (Exc) } \\
{[\mathrm{nm}]}\end{array}$} & \multicolumn{6}{|c|}{ Compound } \\
\hline & & \multicolumn{2}{|c|}{ 1d } & \multicolumn{2}{|c|}{ le } & \multicolumn{2}{|c|}{ If } \\
\hline & & Degassed & $\begin{array}{c}\text { Air- } \\
\text { equili- } \\
\text { brated }\end{array}$ & Degassed & $\begin{array}{l}\text { Air- } \\
\text { equili- } \\
\text { brated }\end{array}$ & Degassed & $\begin{array}{l}\text { Air- } \\
\text { equili- } \\
\text { brated }\end{array}$ \\
\hline 2-Methyl- & 254 & 9 & 4 & - & - & 28 & 21 \\
\hline benzoxazole & $\geq 280$ & 11 & 9 & - & - & 64 & 43 \\
\hline 2-Phenyl- & 254 & - & - & 30 & 22 & 29 & 16 \\
\hline benzoxazole & $\geq 280$ & - & - & 56 & 41 & 55 & 37 \\
\hline
\end{tabular}

azoles depends on the wavelength of excitation as well as on the substituent $R$.

\section{Quinoxalino-quinoxalines}

The condensation product of $N$-methyl-o-phenylenediamine and glyoxal, 17, is a stable compound like 1. However, in contrast to 1 (cf. Scheme 1) only one photodehydrogenation product is formed from 17, namely 5,11-dimethylquinoxalino[2,3-b]quinoxaline (20). In air-equilibrated $\mathbf{C H}$ as solvent the chemical yield is independent of the excitation wavelength ( 254 and $\geq 280 \mathrm{~nm})$ and quite high $(\approx 80 \%)$ provided only small amounts of the solute are converted, i.e. as long as the photoproduct does not appreciably absorb the exciting light. In degassed $\mathrm{CH}$ the yield is lower $(\approx 60 \%)$ under short-wavelength $(254 \mathrm{~nm})$ excitation. Like 5 , the photoproduct has characteristic absorption peaks with maxima at $\lambda_{\max }=368,388,411$ and $437.5 \mathrm{~nm}$ and it fluoresces with high quantum yield $\left(\lambda_{\max }=442,472,506,544\right.$ and $590 \mathrm{~nm}$ ). Surprisingly (cf. Scheme 1), 3,3'-dimethyl-2,2'-bibenzimidazole (18) is not formed in detectable amounts. (Limit of detection $\approx 0.5 \% ; 18$ has strong absorption peaks at 327 and $344.5 \mathrm{~nm}$, where the extinction coefficients of 17 are almost zero.) This is quite in contrast to the case of benzoxazino-benzoxazine 1 where the rearrangement of its sixmembered ring system to the five-membered ring system of 3 is the main photoreaction pathway.

If one monitors the formation of 20 by measuring the absorbance at a given wavelength $E(\lambda)$ as a function of irradiation time $t$, an increase of the rate of formation $[\Delta E(\lambda) / \Delta t]$ is observed at the beginning of the photoreaction. After this induction period, the rate of formation remains constant (provided, of course, that the light absorption has not yet decreased appreciably due to the consumption of starting material). If the irradiation is interrupted for a certain period, the absorbance at the monitoring wavelength still increases further to a final value within a "half life" of about $3 \mathrm{~h}$. If the excitation is continued after this interruption, the rate of formation is the same as before the

\section{Scheme 6}

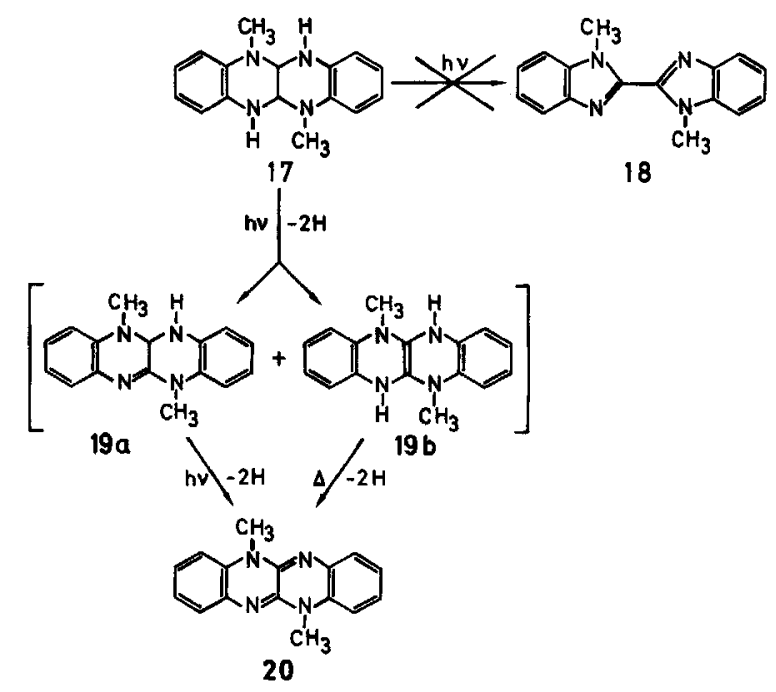


interruption, i.e. the photoreaction continues without a new induction period. An unexposed, dark-stored solution does not change its absorbance.

From these observations we conclude that, in analogy to Scheme 1, two intermediates are formed photochemically: One (labeled 19a in Scheme 6) which has to absorb a second photon to be converted into 20 and another one (19b) which is slowly thermally converted into $\mathbf{2 0}$.

Scheme 7

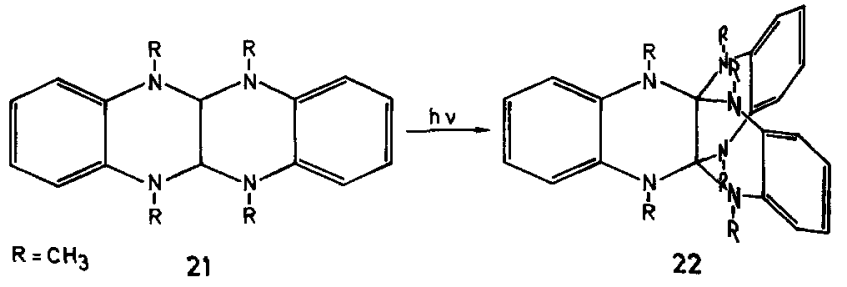

The most surprising photochemical properties exhibits the tetramethyl-substituted derivative $\mathbf{2 1}$ as we reported in a short communication ${ }^{3)}$. Compound $\mathbf{2 1}$ is converted into the propellan-type product 22 in relatively high chemical yield $(11 \%)$ by irradiation of a nitrogen-purged solution of 21 in cyclohexane with a mercury resonance lamp $(\lambda=254$ nm) (Scheme 7).

The propellane structure of $\mathbf{2 2}$ (orthoamide of oxalic acid) has been verified by X-ray analysis ${ }^{31}$. To our knowledge no oxalic acid orthoamide has so far been described in the literature. Besides 22, a large number of other unidentified photoproducts are formed from $\mathbf{2 1}$ in smaller yields.

\section{2,2'-Bibenzothiazole 23}

In contrast to all other derivatives of 1 described in this paper, condensation of $1 \mathrm{~mol}$ of glyoxal with $2 \mathrm{~mol}$ of $\mathrm{N}$ methyl-2-aminothiophenol does not yield a benzothiazinobenzothiazine but the bibenzothiazole 23. The structure of 23 follows from its mass spectrum which shows a peak at the molecular mass $\left(m / z=300, \mathrm{M}^{+}\right)$and, as fragment with the highest mass, a peak at $\mathrm{M}^{+} / 2(m / z=150)$. Irradiation of a degassed solution of 23 in $\mathrm{CH}$ yields the $[1,4]$ benzothiazino $[3,2-b]$ benzothiazine 24. The NMR and UV spectra of starting material and photoproduct are very similar and the elementary analysis shows that the molecular formula of the photoproduct is the same as that of the starting material. The mass spectrum of $\mathbf{2 4}$, however, exhibits besides the $\mathbf{M}^{+}(m / z=300)$ and $\mathbf{M}^{+} / 2(m / z=150)$ peaks two fragments which are 13 mass units $(\mathrm{C}+\mathrm{H})$ larger or smaller than $\mathrm{M}^{+} / 2$. We have observed such fragments only in ring systems like 1. Analogous to 1a (cf. Scheme 2) photooxidation of $\mathbf{2 3}$ does not take place with appreciable yield and the rearrangement $\mathbf{2 3} \rightarrow \mathbf{2 4}$ proceeds with a much lower yield in an air-equilibrated $\mathrm{CH}$ solution.

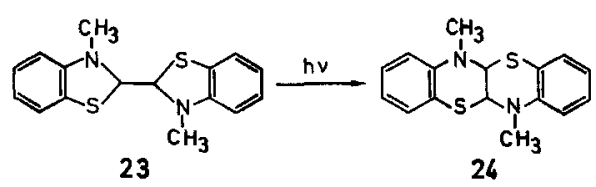

We thank Mrs. A. Heinrich for technical assistance.

\section{Experimental}

Spectra: UV: Perkin-Elmer Model 320. - Fluorescence: Spex Fluorolog. - ${ }^{1}$ H NMR: Bruker WH 270. - MS: Varian MAT CH 17. - Melting points were determined in open capillaries and are uncorrected. - Irradiation experiments were carried out with $10^{-4}$ $M$ solutions. The solutions were degassed by purging with purified nitrogen $\left(<2\right.$ ppm $\left.\mathrm{O}_{2}\right)$. For "short-wavelength" irradiations (254 $\mathrm{nm}$ ) a low-pressure, 15-W mercury lamp (Hanau NN 15/44) was employed and for "long-wavelength" irradiations a medium pressure, 50-W mercury lamp (Osram $\mathrm{Hg} \mathrm{100)}$ ) together with a cut-off filter (Schott WG 280). For irradiations on a preparative scale a Rayonet reactor with 16 lamps $(254 \mathrm{~nm})$ was used and the concentration of the solutions was about $5 \times 10^{-3} \mathrm{M}$. - The solvent used was cyclohexane $(\mathrm{CH})$ (Uvasol quality, Merck-Schuchardt, or for preparative irradiations Baker, p.a.).

5a,6,11a,12-Tetrahydro-6,12-dimethyl[1,4] benzoxazino[3,2-b][1,4] benzoxazine (1 a): $24.6 \mathrm{~g}(0.2 \mathrm{~mol})$ of 2-(methylamino)phenol $\left.{ }^{4}\right)$ was dissolved under nitrogen in $100 \mathrm{ml}$ of ethanol, $19.3 \mathrm{~g}(0.1 \mathrm{~mol})$ of glyoxal ( $30 \%$ in $\mathrm{H}_{2} \mathrm{O}$ ) was added and the solution was heated at reflux for $1 \mathrm{~h}$. After cooling, the product was filtered, washed with a little ethanol and dried; yield $11.55 \mathrm{~g}(43 \%)$, m.p. $159-163^{\circ} \mathrm{C}$. Further purification on an $\mathrm{Al}_{2} \mathrm{O}_{3}$ column (eluant $\mathrm{CH} /$ diisopropyl ether, $3: 1$ by vol.) and recrystallization from ethanol yielded colorless needles, m.p. $163-164^{\circ} \mathrm{C}$. $-\mathrm{UV}(\mathrm{CH}): \lambda_{\max }$ $(\lg \varepsilon)=292 \mathrm{~nm}(3.88), 259(4.15), 211(4.86) .-{ }^{1} \mathrm{H}$ NMR $\left(\mathrm{CDCl}_{3}\right)$ : $\delta=3.2\left(\mathrm{~s}, 6 \mathrm{H}, \mathrm{CH}_{3}\right), 5.25(\mathrm{~s}, 2 \mathrm{H}, \mathrm{CH}), 6.6-7.0(\mathrm{~m}, 8 \mathrm{H}$, arom. H).

\section{$\mathrm{C}_{16} \mathrm{H}_{16} \mathrm{~N}_{2} \mathrm{O}_{2}$ (268.3) Calcd. C 71.62 H 6.01 N $10.44 \mathrm{O} 11.93$} Found C 71.66 H 6.12 N 10.50 O 11.84

5a,6,11a,12-Tetrahydro-5a-methyl[ 1,4]benzoxazino [3,2-b][1,4]benzoxazine (1 b) was prepared according to Murase ${ }^{5)}$; m.p. $218-219^{\circ} \mathrm{C}$ (from ethanol). The MS and the X-ray structure of $\mathbf{1 b}$ have been determined by Barluenga et al. ${ }^{6)}$.

5a,6,11a,12-Tetrahydro-5a-phenyl[ 1,4]benzoxazino [3,2-b][1,4]benzoxazine (1 $\mathrm{c}): 22 \mathrm{~g}(0.2 \mathrm{~mol})$ of 2-aminophenol and $15.2 \mathrm{~g}(0.1$ mol) of phenylglyoxal hydrate were dissolved in $150 \mathrm{ml}$ of toluene and boiled in a Dean-Stark trap until $4.5 \mathrm{ml}$ (theoretical value 5.4 m1) of $\mathrm{H}_{2} \mathrm{O}$ had separated. On cooling, colorless crystals separated [20.2 g $(64 \%)$, m.p. $\left.154-155^{\circ} \mathrm{C}\right]$, after recrystallization from ethanol m.p. $160-161^{\circ} \mathrm{C}$ (ref. ${ }^{2 \text { a) }} 155-157^{\circ} \mathrm{C}$ ).

5a,6,11a,12-Tetrahydro-5a,11a-dimethyl[1,4]benzoxazino[3,2-b]$[1,4]$ benzoxazine (1 d) was prepared according to Kehrmann ${ }^{7]}$; m.p. (from ethanol) $240-241^{\circ} \mathrm{C}$. An X-ray structure of $1 \mathrm{~d}$ has been reported by Barluenga et al. ${ }^{6}$. $-\mathrm{UV}(\mathrm{CH}): \lambda_{\max }(\lg \varepsilon)=289 \mathrm{~nm}$ (3.93), 230 (sh) (4.10), 207 (4.94).

5a,6,11a,12-Tetrahydro-5a,11a-diphenyl[ 1,4]benzoxazino[3,2-b][1,4]benzoxazine (1 e): $22 \mathrm{~g}(0.2 \mathrm{~mol})$ of 2-aminophenol and $21 \mathrm{~g}$ $(0.1 \mathrm{~mol})$ of benzil were dissolved in $150 \mathrm{ml}$ of toluene and boiled in a Dean-Stark trap until $2.9 \mathrm{ml}(0.16 \mathrm{~mol})$ of $\mathrm{H}_{2} \mathrm{O}$ had separated $(\approx 2 \mathrm{~d}$ ). After cooling, $100 \mathrm{ml}$ of toluene was evaporated from the reaction mixture, the residue diluted with $150 \mathrm{ml}$ of ethanol and allowed to stand for $\approx 12 \mathrm{~h}$. Filtration of the precipitate and washing with ethanol yielded $15.1 \mathrm{~g}(39 \%)$ of crude $1 \mathrm{e}$ (m.p. $\approx 206^{\circ} \mathrm{C}$ ), which was recrystallized twice from ethanol to yield colorless crystals with m.p. $211-212^{\circ} \mathrm{C}$. $-\mathrm{UV}(\mathrm{CH}): \lambda_{\max }(\lg \varepsilon)=287 \mathrm{~nm}$, (4.02). $-{ }^{1} \mathrm{H}$ NMR $\left(\mathrm{CDCl}_{3}\right): \delta=4.75(\mathrm{~s}, 2 \mathrm{H}, \mathrm{NH}), 6.6-7.4(\mathrm{~m}$, $18 \mathrm{H}$, arom.). $-\mathrm{MS}(70 \mathrm{eV}): m / z(\%)=392(31)\left[\mathrm{M}^{+}\right], 285(43)$, 284 (45), 196 (100), 195 (100).

$$
\mathrm{C}_{26} \mathrm{H}_{20} \mathrm{~N}_{2} \mathrm{O}_{2} \text { (392.5) Calcd. C 79.57 H 5.14 N 7.14 O } 8.15
$$

$$
\text { Found C } 79.38 \text { H } 5.21 \text { N } 7.13 \text { O } 8.33
$$

5a,6,11a,12-Tetrahydro-5a-methyl-11a-phenyl 1,4 Jbenzoxazino[3,2-b]/ 1,4]benzoxazine (1 $\mathrm{f}$ ) was prepared according to Murase ${ }^{5)}$; 
m.p. (from ethanol) $218^{\circ} \mathrm{C}$. The $\mathrm{X}$-ray structure of $1 \mathrm{f}$ has been determined by Barluenga et al. ${ }^{6}$. $-\mathrm{UV}(\mathrm{CH}): \lambda_{\max }(\lg \varepsilon)=288 \mathrm{~nm}$ (3.97), 207 (4.99).

2-[1-(2-Benzoxazolyl)ethylideneamino]phenol (9). - A) 1-(2Benzoxazolyl)ethanol: $66 \mathrm{~g}(0.6 \mathrm{~mol})$ of 2 -aminophenol and $60 \mathrm{~g}$ $(0.6 \mathrm{~mol})$ of d,l-lactic acid $(90 \%$ in water) were heated under stirring on an oil bath to $140^{\circ} \mathrm{C}$ until $16.5 \mathrm{ml}$ of $\mathrm{H}_{2} \mathrm{O}$ was formed $(\approx 4 \mathrm{~h}$ ). Without allowing to cool down the liquid crude product was distilled with a Vigreux column $\left(140^{\circ} \mathrm{C}, 13\right.$ Torr $)$. The distillate was again distilled with a Widmer column yielding $72.0 \mathrm{~g}(74 \%)$ of a nearly colorless, viscous oil, b.p. $137^{\circ} \mathrm{C}$ (13 Torr). $-{ }^{1} \mathrm{H}$ NMR $\left(\mathrm{CDCl}_{3}\right): \delta=1.73\left(\mathrm{~d}, J=5 \mathrm{~Hz}, 3 \mathrm{H}, \mathrm{CH}_{3}\right), 4.30(\mathrm{~s}, 1 \mathrm{H}, \mathrm{OH}), 5.15$ (q, $J=5 \mathrm{~Hz}, 1 \mathrm{H}, \mathrm{CHOH}), 7.15-7.8(\mathrm{~m}, 4 \mathrm{H}$, arom. $\mathrm{H})$.

\section{$\mathrm{C}_{9} \mathrm{H}_{9} \mathrm{NO}_{2}$ (163.2) Calcd. C 66.25 H 5.56 N 8.58 O 19.61 Found C 66.34 H 5.58 N 8.60 O 19.75}

B) 1-(2-Benzoxazolyl)ethanone (12) was prepared analogously to the method of Pratt et al. ${ }^{8)}$. $135 \mathrm{~g}\left(1.5 \mathrm{~mol}\right.$ ) of $\mathrm{MnO}_{2}$ (freshly precipitated) was suspended in 1.51 of $\mathrm{CH}, 49 \mathrm{~g}(0.3 \mathrm{~mol})$ of 1-(2benzoxazolyl)ethanol was added, and the mixture was boiled in a Dean-Stark trap for $16 \mathrm{~h}$ under vigorous stirring. After cooling, the reaction mixture was separated from $\mathrm{MnO}_{2}$ and after evaporation of the solvent $44 \mathrm{~g}$ of a dark oil remained. This oil was distilled with a Widmer column (13 Torr) until a boiling point of $137^{\circ} \mathrm{C}$ was reached. The distillate $(\approx 15 \mathrm{~g})$ was collected in a saber-shaped flask and chromatographed on a silica column with $\mathrm{CH} /$ diethyl ether $(1: 1)$ as eluant. Recrystallization from $\mathrm{CH}$ yielded $9.2 \mathrm{~g}(19 \%)$ of 12 as colorless crystals with m.p. $80-81^{\circ} \mathrm{C}$. $-{ }^{1} \mathrm{H}$ NMR $\left(\mathrm{CDCl}_{3}\right)$ : $\delta=2.8\left(\mathrm{~s}, 3 \mathrm{H}, \mathrm{CH}_{3}\right), 7.35-7.95(\mathrm{~m}, 4 \mathrm{H}$, arom. $\mathrm{H})$.

\section{$\mathrm{C}_{9} \mathrm{H}_{7} \mathrm{NO}_{2}$ (161.2) Calcd. C 67.08 H 4.38 N 8.69 O 19.86} Found C 67.19 H 4.47 N 8.68 O 19.76

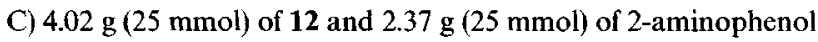
were dissolved in $50 \mathrm{ml}$ of toluene and boiled in a Dean-Stark trap until $\approx 0.3 \mathrm{ml}(17 \mathrm{mmol})$ of water had separated. After evaporation of the solvent the reaction mixture was chromatographed on a silica column with $\mathrm{CH} /$ diisopropyl ether (1:1), yielding $4.08 \mathrm{~g}(68 \%)$ of crude product. After recrystallization from toluene $1.28 \mathrm{~g}(20.3 \%)$ of 9 was obtained as yellow crystals, m.p. $127-128^{\circ} \mathrm{C}$. - UV $(\mathrm{CH})$ : $\lambda_{\max }(\lg \varepsilon)=374 \mathrm{~nm}(3.99), 297(4.20) .-{ }^{1} \mathrm{H} \mathrm{NMR}\left(\mathrm{CDCl}_{3}\right): \delta=$ 3.65 (s, $\left.3 \mathrm{H}, \mathrm{CH}_{3}\right), 6.5$ (br. s, $\left.1 \mathrm{H}, \mathrm{OH}\right), 6.7-7.9(\mathrm{~m}, 8 \mathrm{H}$, arom. $\mathrm{H}$ ). Upon addition of $\mathrm{CH}_{3} \mathrm{OD}$, the signals at $\delta=6.5$ and 3.65 disappear.

$$
\begin{aligned}
& \mathrm{C}_{15} \mathrm{H}_{12} \mathrm{~N}_{2} \mathrm{O}_{2} \text { (252.3) Calcd. C 71.42 H } 4.79 \text { N } 11.10 \text { O } 12.68 \\
& \text { Found } \mathrm{C} 71.49 \text { H } 4.78 \text { N } 11.03 \text { O } 12.58
\end{aligned}
$$

5,5a,6,11,11a,12-Hexahydro-5,11-dimethylquinoxalino[2,3-b/quinoxaline (16): $24 \mathrm{~g}(0.15 \mathrm{~mol})$ of $\mathrm{N}$-methyl-2-nitroaniline (Aldrich, $95 \%)$ was reduced with $40 \mathrm{~g}(0.34 \mathrm{~mol})$ of granulated tin and 180 $\mathrm{ml}$ of conc. $\mathrm{HCl}$. The acidic solution of the $N$-methyl-1,2-phenylenediamine was added dropwise under nitrogen with vigorous stirring to a solution of $240 \mathrm{~g}(6 \mathrm{~mol})$ of $\mathrm{NaOH}$ in $1 \mathrm{l}$ of $\mathrm{H}_{2} \mathrm{O}$. About 1.51 of this solution was distilled under nitrogen whereby the water had to be replenished from time to time. The distillate contained practically all of the amine, to which $14.5 \mathrm{~g}(0.075 \mathrm{~mol})$ of glyoxal (30\% in water) was added with vigorous stirring. After $1-2 \mathrm{~min}$ the solution became turbid and crystallization started. After $\approx 12 \mathrm{~h}$ the precipitate was filtered off, washed with $\mathrm{H}_{2} \mathrm{O}$ and dried; yield $19.15 \mathrm{~g}\left(96^{\circ}\right)$ ) of crude product; m.p. $144-150^{\circ} \mathrm{C}$ (dec.). Recrystallization (two times from 2-propanol, light-protected and under nitrogen) yielded $11.45 \mathrm{~g}(57 \%)$ of colorless crystals which melted under decomposition, starting at $150^{\circ} \mathrm{C}$ - ${ }^{1} \mathrm{H}$ NMR $\left(\mathrm{CDCl}_{3}\right): \delta=3.07\left(\mathrm{~s}, 6 \mathrm{H}, \mathrm{NCH}_{3}\right), 3.7$ (br. s, $\left.2 \mathrm{H}, \mathrm{NH}\right), 4.67(\mathrm{~s}, 2 \mathrm{H}$,
$\mathrm{CH}), 6.35-6.85\left(\mathrm{~m}, 8 \mathrm{H}\right.$, arom. H). $-\mathrm{UV}(\mathrm{CH}): \lambda_{\max }(\lg \varepsilon)=307$ $\mathrm{nm}(4.00), 250(\mathrm{sh})(4.08), 222$ (4.78).

$$
\mathrm{C}_{16} \mathrm{H}_{18} \mathrm{~N}_{4}(266.35) \quad \text { Calcd. C } 72.15 \mathrm{H} 6.81 \mathrm{~N} 21.04
$$
Found C 72.24 H 6.91 N 21.05

5,5a,6,11,11a,12-Hexahydro-5,6,11,12-tetramethylquinoxalino/ 2,3b]quinoxaline (21) and 5,6,11,12-Tetrahydro-5,6,11,12,13,20-hexamethyl-5a,1 1a-(imino [1,2]benzenoimino) quinoxalino [2,3-b]quinoxaline (22): The preparation of $\mathbf{2 1}$ and $\mathbf{2 2}$ has been described in ref. ${ }^{3)}$.

2,2',3,3'-Tetrahydro-3,3'-dimethyl-2,2'-bibenzothiazole (23): $50 \mathrm{~g}$ of $\mathrm{KOH}$ was dissolved under nitrogen in $300 \mathrm{ml}$ of ethanol, $45 \mathrm{~g}$ $(0.27 \mathrm{~mol})$ of 3 -methylbenzothiazolin-2-one $\mathrm{e}^{9)}$ was added and the mixture was heated at reflux for $5 \mathrm{~h}$. After cooling, the precipitated potassium salt was decanted and the ethanol evaporated. The oily residue and the potassium salt were dissolved in water, the solution was acidified with $\mathrm{HCl}(\mathrm{pH} \approx 5), 27 \mathrm{~g}(0.14 \mathrm{~mol})$ of glyoxal $(30 \%$ in water) was added and the solution was heated at reflux under nitrogen for $22 \mathrm{~h}$. After cooling, $40.0 \mathrm{~g} \mathrm{(91 \% )}$ of crude 23 (m.p. $120-140^{\circ} \mathrm{C}$ ) precipitated. Recrystallization (three times from ethanol) yielded $8.8 \mathrm{~g}(20 \%)$ of colorless crystals (m.p. $155-156^{\circ} \mathrm{C}$ ) and $25 \mathrm{~g}$ of less pure material from the mother liquor. - $\mathrm{UV}(\mathrm{CH})$ : $\lambda_{\max }(\mathrm{lg} \varepsilon)=313 \mathrm{~nm}(3.95), 260(\mathrm{sh})(3.91), 231.5(4.68) .-{ }^{1} \mathrm{H}$ NMR $\left(\mathrm{CDCl}_{3}\right): \delta=3.05\left(\mathrm{~s}, 6 \mathrm{H}, \mathrm{CH}_{3}\right), 4.98(\mathrm{~s}, 2 \mathrm{H}, \mathrm{CH}), 6.4-7.1(\mathrm{~m}, 8 \mathrm{H}$, arom. H). - MS: $m / z(\%)=300(3)\left[\mathrm{M}^{+}\right], 150(100), 109(32)$.

\section{$\mathrm{C}_{16} \mathrm{H}_{16} \mathrm{~N}_{2} \mathrm{~S}_{2}$ (300.5) Calcd. C $63.96 \mathrm{H} 5.37 \mathrm{~N} 9.32 \mathrm{~S} 21.34$} Found C 64.06 H 5.41 N 9.36 S 21.28

5a,6,11a,12-Tetrahydro-6,12-dimethyl 1,4]benzothiazino[3,2-b][1,4]benzothiazine (24): $1 \mathrm{~g}$ of 23 was dissolved in 1.31 of $\mathrm{CH}$ and irradiated $(254 \mathrm{~nm})$ for $6 \mathrm{~d}$ under nitrogen in a Rayonet reactor. The quartz vessel which contained the solution had to be cleaned every $24 \mathrm{~h}$ from a dark precipitate on its walls. The solvent was evaporated and the photoproduct chromatographed on an $\mathrm{Al}_{2} \mathrm{O}_{3}$ column with $\mathrm{CH} /$ diethyl ether $(1: 1)$ as eluant. Recrystallization from ethanol yielded $84 \mathrm{mg}(8.4 \%)$ of colorless crystals, m.p. $166-167^{\circ} \mathrm{C}$ - UV $(\mathrm{CH}): \lambda_{\max }(\lg \varepsilon)=316 \mathrm{~nm}(3.96), 232(4.75)$. ${ }^{1} \mathrm{H} \mathrm{NMR}\left(\mathrm{CDCl}_{3}\right): \delta=3.02\left(\mathrm{~s}, 6 \mathrm{H}, \mathrm{CH}_{3}\right), 5.05(\mathrm{~s}, 2 \mathrm{H}, \mathrm{CH}), 6.4-7.1$ $(\mathrm{m}, 8 \mathrm{H}$, arom. $\mathrm{H})$.

$\mathrm{C}_{16} \mathrm{H}_{16} \mathrm{~N}_{2} \mathrm{~S}_{2}$ (300.5) Calcd. C 63.96 H 5.37 N 9.32 S 21.34 Found C 64.22 H 5.15 N 9.41 S 21.10

\section{CAS Registry Numbers}

1a: $124855-82-9$ / 1 b: 124855-83-0 / 1c: $124855-84-1$ / 1d: $124855-$ 85-2 / 1e: $124855-86-3$ / 1f: $124855-87-4$ / 6: 124855-93-2 / 9: 124855-89-6 / 12: 122433-29-8 / 16: 124855-90-9 / 20: 15805-70-6 21: 13784-23-1 / 22: 124855-94-3 / 23: 124855-91-0 / 24: 124855 . 92-1 / 2-aminophenol: 95-55-6 / glyoxal: 107-22-2 / phenylglyoxal: 1074-12-0 / benzil: 134-81-6 / 1-(2-benzoxazolyl)ethanol: $124855-$ 88-5 / d,1-lactic acid: 598-82-3 / N-methyl-2-nitroanilinc: $612-28-2$ / 3-methylbenzothiazolin-2-one: 2786-62-1 / 2-phenylbenzoxazole: 833-50-1 / benzoxazole: 273-53-0 / 2-methylbenzoxazole: 95-21-6 / 2-(methylamino)phenol: $611-24-5$

1) E. Tauer, K.-H. Grellmann, E. Kaufmann, M. Noltemeyer, Chem. Ber. 119 (1986) 3316.

2) 2a) E. Belgodere, R. Bossio, V. Parrini, R. Pepino, J. Heterocycl. Chem. 14 (1977) 957. - 26) E. Belgodere, R. Bossio, V. Parrini, R. Pepino, J. Heterocycl. Chem. 14 (1977) 997. - ${ }^{2 c)}$ E. Belgodere, R. Bossio, V. Parrini, R. Pepino, J. Heterocycl. Chem. 17 (1980) 1625. - 2d) E. Belgodere, R. Bossio, V. Parrini, R. Pepino, J. Heterocycl. Chem. 17 (1980) 1629. 
3) E. Tauer, K.-H. Grellmann, M. Noltemeyer, G. M. Sheldrick, Angew. Chem. 101 (1989) 350; Angew. Chem. Int. Ed. Engl. 28 (1989) 338.

4) G. De. W. Anderson, F. Bell, J. Chem. Soc. 1949, 2668.

5) J. Murase, Bull. Chem. Soc. Jpn. 33 (1960) 59.

6) J. Barluenga, F. Aznar, R. Liz, M.-P. Cabal, F. H. Cano, C. Foces-Foces, Chem. Ber. 119 (1986) 887.
${ }^{7}$ F. Kehrmann, Ber. Dtsch. Chem. Ges. 28 (1895) 343.

${ }^{8)}$ E. F. Pratt, J. F. Van de Castle, J. Org. Chem. 26 (1961) 2973.

9) H. Fenner, R. W. Grauert, P. Hemmerich, Liebigs Ann. Chem. 1978, 193.

$[373 / 89]$ 